\title{
ANALISIS DIAGRAM FASOR MOTOR INDUKSI DENGAN VIRTUAL INSTRUMENT
}

\author{
Juhana Aditya, ST, $\mathrm{MT}^{1}$, Fredy Dwifanto ${ }^{2}$ \\ ${ }^{1,2,3}$ ProdiTeknikElektro UNPAM \\ Jln. Puspiptek Raya No 46Buaran, Setu - Tangerang Selatan 15310 \\ E-mail : Fredydwi@yahoo.com
}

\begin{abstract}
ABSTRAK
Analisis diagram fasor motor induksi yang cakupanya lebih luas dan dapat dimanfaatkan bagi lembaga - lembaga lainya khususnya lembaga pendidikan dalam penyampaian belajar mengajar melalui media elektronik agar bisa mengimbangi kemajuan teknologi elektronik yang begitu pesat. Memberikan siswa kemampuan untuk mengukur, menganalisa sinyal hidup, akusisi datanya sangat portable dan diagram fasor tidak bisa diamati secara langsung harus dengan mengunkan virtual intrument. Dapat di gunakan dimana saja dan kapan saja sehingga dengan mudah untuk di gunakan dan juga biaya rendah, dengan mengunakan perangkat NI myDAQ.

Tujuan penulis menganalisa " Diagram fasor motor induksi dengan virtual instrument " Supaya para pengguna akan lebih mudah dalam membaca hasil dalam pengukuran dan dapat membandingkan sekaligus menganalisa tegangan dan arus pada motor induksi tiga fasa dengan mengunakan beban torsi yang divariasikan dari beban $0,5 \mathrm{~s} / \mathrm{d} 2,5 \mathrm{Nm}$, waktu (T) dan frekwensi ( $\mathrm{Hz}$ ), hasil pengukuran mengetahui perbedaan fasa antara tegangan dan fasa arus, mengetahui dua sifat faktor daya "Leading" dan faktor daya " lagging ".
\end{abstract}

Kata kunci : Motor 3- Fasa, NI myDAQ dan LabVIEW

\begin{abstract}
The analysis of phasor diagrams of induction motors is wider and can be utilized for other institutions, especially educational institutions in the delivery of teaching and learning through electronic media in order to balance the advancement of electronic technology so rapidly. Gives students the ability to measure, analyze the live signal, data acquisition is very portable and phasor diagram can not be observed directly must by using virtual intrument. Can be used anywhere and anytime so it is easy to use and also low cost, by using the mydaq NI device.

The author's purpose is to analyz "Induction motor faset diagram with virtual instrument" In order for the users to read more easily in the measurement and can compare as well as analyzing the voltages and currents of three phase induction motors by using torque loads varied from 0.5 to $2.5 \mathrm{Nm}$, time $(\mathrm{T})$ and frequency $(\mathrm{Hz})$, the measurement results know the phase difference between voltage and phase current, find out two power factor properties Leading "and power factor" lagging ".
\end{abstract}

Keywords : Motor 3 - Fasa, NI myDAQ and LabVIEW 


\section{PENDAHULUAN}

Kemajuan teknologi dibidang elektronik dewasa ini berkembang begitu pesat, sehingga berpengaruh dalam pembuatan suatu peralatan elektronik, sehingga berkembanglah alat-alat canggih baik dari segi hardware dan software yang satu sama lain saling berkaitan dan saling mendukung, sehingga terciptalah suatu peralatan yang mudah dimengerti dan mudah digunakan. Sekarang ini masih banyak alat-alat untuk praktikum, baik untuk pengukuran atau menganalisa masih dalam bentuk konvesional, untuk mengetahui bahwa gelombang sinusoidal yang memiliki frekuensi yang sama bisa memiliki perbedaan fase yang menyatakan perbedaan sudut keduanya.

Salah satu analisis "mendahului", "tertinggal", "sefasa" dan "dua fasa" digunakan untuk menujukan hubungan antara satu gelombang dengan gelombang sebuah sinus pada satuan waktu. Dimana pernyataan sebuah gelombang dalam bentuk matematika saja terkadang sulit untuk divisualisasikan, sehingga untuk menyatakan perbedaan sudut atau fasa gelombang dapat dipresentasikan secara grafiks mengunakan domain ruang atau fasor. Maka dengan permasalahan yang dihadapi untuk praktikum tersebut penulis merancang "diagram fasor motor induksi" menggunakan virtual instruments, dimana pada virtualinstrument ini dapat mengetahui perbedaan fasa antara tegangan dan arus, bahkan hasilnya bisa disimpan dalam bentuk file. Virtual instrument hanya menggunakan beberapa perangkat diantaranya adalah media pengukuran yaitu sebuah alat praktikum, $m y D A Q$ dan $\mathrm{PC} /$ komputer yang didalamnya sudah di lengkapi software LabView, sehingga dalam praktikum merasa lebih mudah dalam memahami hasil dari praktikum, dan memudahkan dalam pengambilan data.

Praktikum menggunakan virtual instrument yang terdiri dari LabView dan $m y D A Q$ masih jarang digunakan di Indonesia, LabView ini merupakan sebuah software pemograman yang diproduksi oleh National Instrument dengan konsep berbeda. LabView ini pemogramannya menggunakan pemograman berbasis grafis, myDAQ merupakan suatu perangkat akuisisi data yang memberikan kemampuan untuk mengukur dan menganalisa sinyal. myDAQ sangat portabel sehingga dapat digunakan di lingkungan laboratorium dan alat-alat standart industri, bahkan dilingkungan pelajar khususnya didunia pendidikan untuk digunakan sebagai alat praktikum, sehingga para pelajar lebih mengenal dan mahir dalam menggunakan virtual instrument. 
TEORI.

Pengukuran rangkaian motor induksi menggunakan alat ukur $m y D A Q$, pengukuran ini akan menampilkan bentuk grafik dari rangkaian motor induksi gelombang sebuah sinus dalam satuan waktu. Rangkaian yang akan dilakukan pengukuran adalah rangkaian motor induksi tiga fasa.

\subsection{Pengukuran rangkaian gelombang} sinusoidal dalam Domain/Satuan Waktu menggunakan alat ukur NI myDAQ.

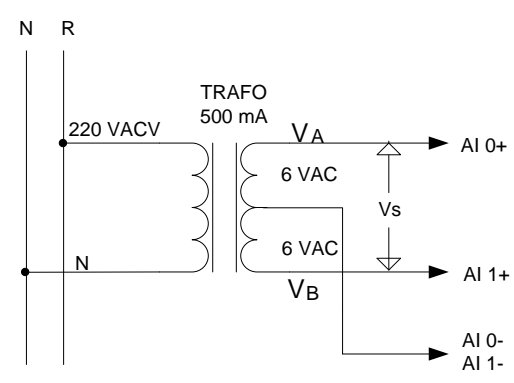

Gambar 2.1.Rangkain pengukuran tegangan trafo sekunder.

Dari hasil pengukuran rangkaian pada output trafo CT menggunakan alat ukur NI myDAQ, dapat diperoleh hasil sesuai dengan gambar 2.2. Hasil grafik tersebut menunjukan bahwa output tegangan pada trafo CT masih berbentuk gelombang sinusiodal, dan dikarenakan menggunakan trafo CT maka keluarannya berbeda $180{ }^{\circ}$ sehingga sehingga terdapat 2 buah gelombang yang berbeda.

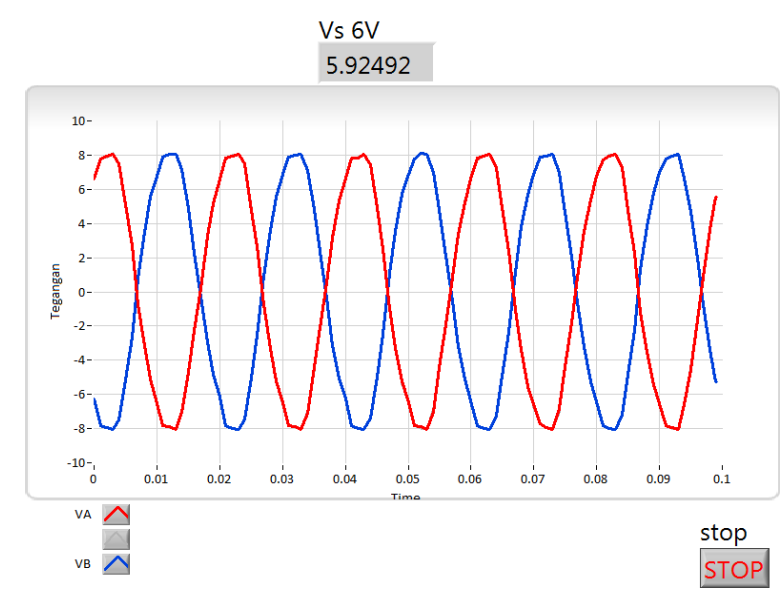

Gambar 2.2.Grafik hasil pengukuran tegangan trafo sekunder (Vs).

\section{METODE PENELITIAN}

Tahapan terpenting adalah perancangan yang baik dan sistematis, akan memberikan kemudahan dalam proses penyelesaian pembuatan alat. Perancangan alat ini mempunyai tujuan, yaitu untuk mendapatkan suatu alat atau sistem yang baik seperti yang diharapkan. Pada penelitian ini menggunakan metode eksperimen.

\section{HASIL DAN PEMBAHASAN}

\subsection{Blok Diagram Rangkaian Motor} Induksi

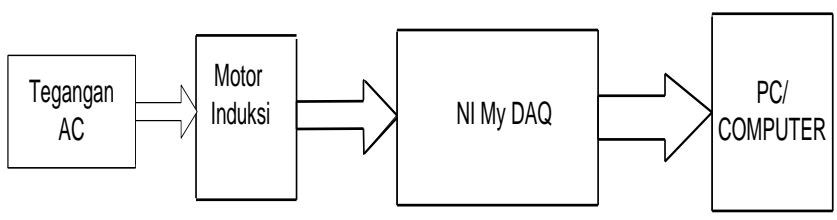

4.2. Pembuatan Antar Muka Dengan

\section{Komputer}


Untuk mempermudah dalam pengukuran suatu rangkaian penulis menggunakan software LabView dan alat instrument yaitu NI myDAQ, dengan desain antar muka pada computer.

Berikut ini desain antar muka dengan komputer :

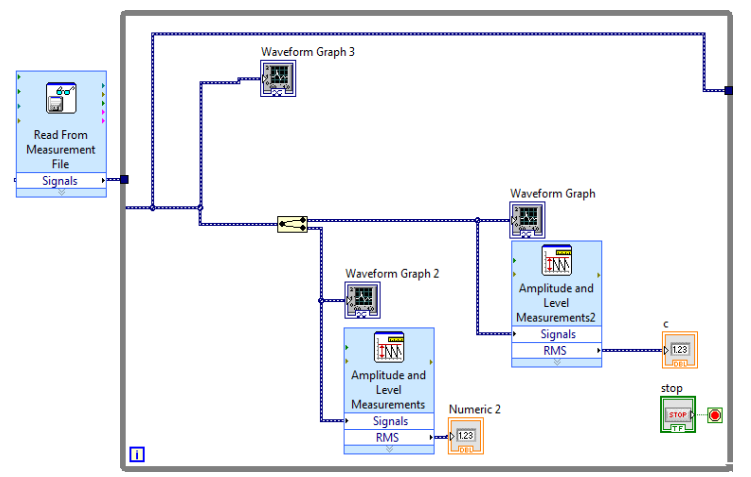

Gambar 4.1. Blok Diagram menggunakan Read From Measurement

Untuk pembuatan program, maka digunakan model blok diagram dari program LabView, didalamnya terdapat icon-icon yang akan digunakan untuk pemograman. Untuk pengukuran digunakan icon pemograman yaitu :

\subsubsection{DAQ Asisstant.}

$D A Q$ Asisstant ini merupakan pengembangan dari menu blok diagram ekpress yang didalamnya terdapat input yaitu DAQ Asisstant, berguna sebagai program input yang meneruskan perintah dari luar. Input yang dapat digunakan yaitu : digital input, analog input. $D A Q$ Asisstant memerlukan beberapa pengaturan sesuai dengan kebutuhan masukannya.

\subsubsection{While loop}

While loop merupakan pengembangan dari menu blok diagram programming yang didalamnya terdapat icon Structures, While loop ini berfungsi sebagai looping.

\subsubsection{Read From Measurement File}

Read From Measurement File berfungsi sebagai pembaca data tersimpan dari hasil pengukuran yang telah dilakukan. File tersebut disimpan dalam bentuk format yang diinginkan. Read From Measurement File sangat berguna untuk membandingkan hasil pengukuran dengan hasil pengukuran yang. Pada Read From Measurement File ada hubungannya dengan Write toMeasurement File, apabila menyimpan hasil pengukuran dalam format Microsoft Office Excel, maka hasil pengukuran tidak bisa ditampilkan kembali kedalam bentuk Waveform Graphic, tetapi penyimpanan hasil pengukuran dapat disimpan kedalam bentuk Text LabView Measurement (LVM), sehingga hasil pengukuran dapat ditampilkan kembali 
dalam bentuk Waveform Graphic dan kedalam format bentuk Microsoft Office Excel.

\subsubsection{Write to Measurement File}

Pada icon Write to Measurement File, hasil dari pengukuran dapat disimpan ke dalam bentuk Text LabView Measurement (LVM), maka disaat membutuhkan data pengukuran dapat dilihat kembali menggunakan icon Read From Measurement File. Sehingga hasil pengukuran dapat dilihat kembali ke dalam bentuk Front Panel. Blok Diagram dan dapat disimpan kembali kedalam format Microsoft Office Excel. Apabila hasil pengukuran disimpan kedalam bentuk Microsoft office excel, maka hasil dari pengukuran tidak dapat ditampilkan kedalam bentuk Front Panel dan Blok Diagram. Gambar blok diagram dapat dilihat pada gambar 2.1.

\subsubsection{Front panel.}

Pada front panel ada beberapa kontrol yang digunakan sesuai dengan aplikasi pengukuran. Untuk kebutuhan pengukuran saat ini digunakan kontrol numeric indicator sebagai pembaca tegangan dalam bentuk angka decimal, dan untuk grafik digunakan Waveform, yang terlebih dahulu merubah skala amplitudonya ditentukan yaitu, untuk tegangan minimum diatur pada posisi -10 volt dan tegangan maksimum pada posisi +10 volt dikarenakan tegangannya masih berupa tegangan peak to peak (Vpp).

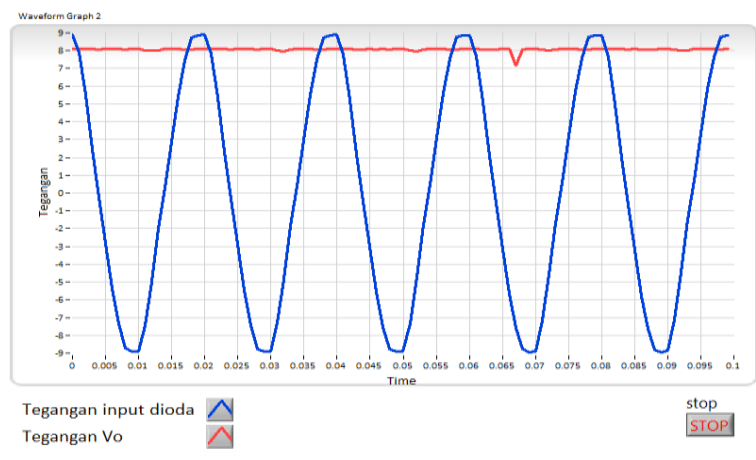

Gambar 4.2.Contoh front panel.

\subsection{Rangkaian Pengukuran Tegangan dan Arus Motor Induksi.}

Rangkaian pengukuran tegangan dan arus pada Motor Induksi tiga fasa dengan dua gelombang sinusoidal pada frekuensi yang sama dengan mengunakan fariabel torsi, yang terdiri dari :

\subsubsection{Rangkaian pengukuran tegangan} Motor Induksi.

Pada pengukuran tegangan pada motor induksi mengunakan tranformer step down . Pengukuran pada tegangan primer tranformer (Vo), dan pengukuran pada tegangan input motor di ambil satu phase secara bergantian atau tegangan input (Vs). Transformer yang digunakan 
mempunyai kemampuan dialiri arus sebesar $500 \mathrm{~mA}$, sedangkan untuk MyDAQ digunakan analog input yaitu, untuk tegangan sekunder trafo (Vs) menggunakan AI0+ dan AI0-, sedangkan untk tegangan input transformer (Vo) digunakan mengukur motor.

Untuk terminal $\mathrm{AIO}+$ dan $\mathrm{AIO}$ - pada alat MyDAQ digunakan untuk mengukur tegangan scunder pada motor bintang $(\mathrm{Y})$ yang akan ditampilkan pada komputer dalam bentuk Sinusoidal, sedangkan Input transformer di gunakan mengukur tegangan pada phase motor .

ditampilkan pada komputer dalam bentuk setengah gelombang penuh. Berikut gambar rangkaian pengukuran tegangan

\section{Motor Induksi.}

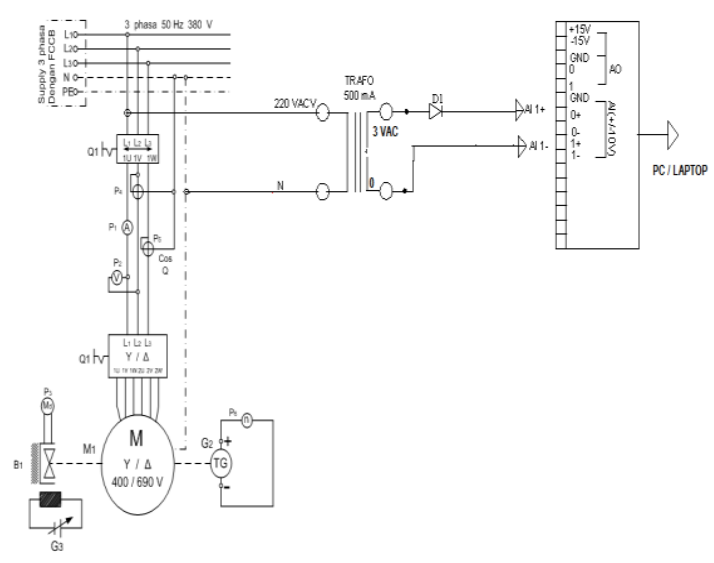

Gambar 4.3.Rangkaian pengukuran tegangan dengan tranformer step down.

\subsubsection{Rangkaian pengukuran arus Motor Induksi.}

Pada rangkaian motor induksi mengunakan sensor arus 100A/ $50 \mathrm{~mA} \mathrm{\&}$ resisstor 20W, $40 \mathrm{ohm}$. Pengukuran pada arus primer Sensor arus (Io), dan pengukuran pada arus input motor di ambil satu phase secara bergantian atau arus input (Is). Sensor arus yang digunakan mempunyai kemampuan dialiri arus sebesar $100 \mathrm{~A} / 50 \mathrm{~mA}$, ressistor untuk memproteksi lonjakan tegangan supaya tidak merusak NI MyDAQ karena tegangan input yang di ijinkan $10 \mathrm{~V}$, MyDAQ digunakan analog input yaitu, untuk tegangan sekunder trafo (Is) menggunakan AI0+ dan AI0-, sedangkan untk arus input sensor arus (Io) digunakan mengukur motor.

Untuk terminal AI0+ dan AI0- pada alat MyDAQ digunakan untuk mengukur arus scunder pada motor bintang (Y) yang akan ditampilkan pada komputer dalam bentuk Sinusoidal, sedangkan Input transformer di gunakan mengukur tegangan pada phase motor .

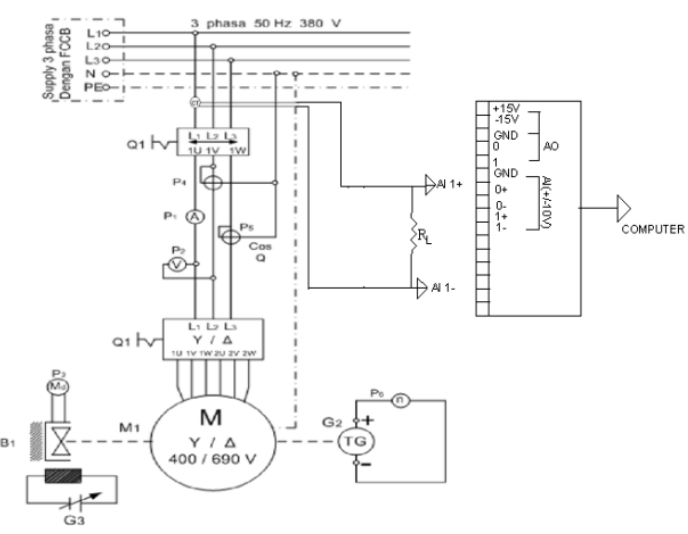


Gambar 4.4.Rangkaian pengukuran arus dengan optocopler/sensor arus.

Berikut gambar hasil pengukuran rangkaian diatas menggunakan NI MyDAQ :

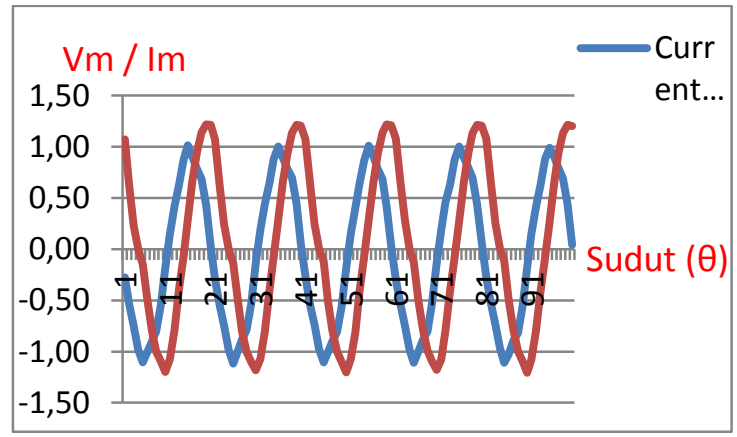

Gambar 4.5. Gelombang tegangan dan arus pada beban $0,5 \mathrm{Nm}$.

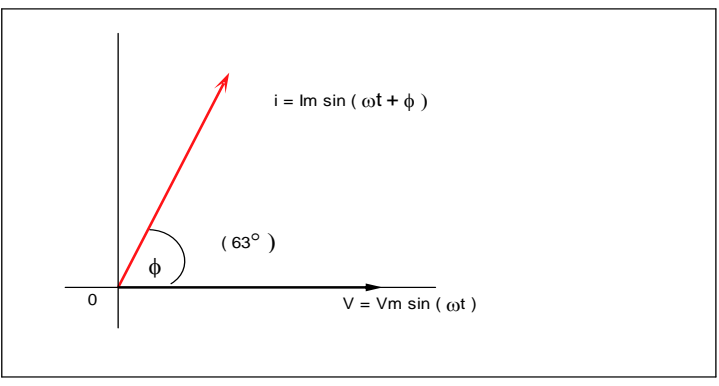

Gambar 4.6. Diagram fasor tegangan dan arus pada beban $0,5 \mathrm{Nm}$.

Dari hasil pengukuran yang telah dilakukan pada gambar 4.5, dan 4,4 tegangan dan arus pada beban $0,5 \mathrm{Nm}$ di peroleh periode $(\mathrm{T})=$ $20 \mathrm{~mm} \mathrm{sec}$ dan frekwensi $\mathrm{f}=50 \mathrm{~Hz}$, sedangkan perbedaan fasa antara tegangan dan fasa arus sebesar $(\boldsymbol{\phi})=63^{\circ}$, dimana fasa arus mendahului dari fasa tegangan (Leading ) dan beban bersifat Kapasitif.

\section{Keterangan :}

Pada gambar 4.5 pembacaan NST ( Nilai Skala Terkecil) untuk waktu $=0,05($ mili second) gambar 4.6 pembacaan NST untuk sudut $(\boldsymbol{\phi})$ NST : $18^{\circ}$. dan frekuensi $\mathrm{f}=1 / \mathrm{T}$.

\section{KESIMPULAN}

1. Pengukuran pada fasa $\mathrm{R}$ dengan beban torsi 0,$5 ; 1,5$ dan $2,5 \mathrm{Nm}$ hasil pengukuran menunjukan fasa arus mendahului fasa tegangan (Leading) jadi beban bersifat kapasitif , sedangkan pada beban torsi 1,0 dan 2,5 $\mathrm{Nm}$ fasa arus tertinggal dari fasa tegangan beban bersifat induktif

2. Pengukuran pada fasa $S$ dengan beban torsi $0,5 \mathrm{Nm}$ fasa arus mendahului fasa tegangan ( Leading), sedangkan pada beban 1,0 ;1,5; dan 2,5 $\mathrm{Nm}$ fasa arus tertinggal dari fasa tegangan ( Lagging) dan dengan beban 2,0 fasa arus dan tegangan terjadi sefasa dengan sudut fasor $90^{\circ}$.

3. Pengukuran pada fasa $\mathrm{T}$ dengan beban 0,$5 ; 1,5$ dan $2,0 \mathrm{Nm}$ fasa arus mendahului fasa tegangan (Leading) dan beban bersifat kapasitif, dengan beban torsi 1,0 dan 2,5 $\mathrm{Nm}$ fasa arus tertinggal dari fasa tegangan (Lagging).

4. Dengan mevariasikan beban torsi pada motor maka terjadi perubahan sudut fasa antara arus dan tegangan. 
5. Dengan menaikan beban torsi pada motor maka terjadi kenaikan arus, cosphi dan daya listriknya sedangkaan tegangan relatif stabil.

6. Untuk analisa fasor arus dan tegangan juga analisa gelombang sinusoidal dari alat NI MyDAQ perlu dilakukan perhitungan Per-Unti ( PU).

7. Diagram fasor hanya digunakan pada gelombang sinusoidal AC.

\section{DAFTAR PUSTAKA}

[1] Yoga Dwi Haryoko Tesis FT Elektro UI Analisa Putaran Motor dengan Lab VIEW Depok, 2012.

[1] LabVIEW Tutorial LABORATORY COURSE ON INTERFACES AND DATA ACQUISITION by Selcuk Cihangir and Simon Kwan, Fermilab, USA Marleigh Sheaff, University of Wisconsin, USA Kerem Cankocak, Mugla University, TURKEY

[2] Rumus- rurmus praktis teori perhitungan instalasi listrik

[5] Zuriman Anthony,ST.,MT Jurnal study pengaruh perubahan frekwensi sumber terhadap faktor daya motor induksi.

[6] National instruments, what is NI my DAQonline2013. http://www.ni.com

[7]Zaenab Muslimin Rangkaian listrik1

[9] Rangkaian Arus Bolak Balik, Listrik,Daya,Resonansi,Pengertian, Fungsi, Resistor, Induktif, Kapasitor, Seri RLC, Rumus, Rangkaian Arus Bolak cyber. blogspot.com

[10] Yusnita, Hendro Tjahjono Teknik Elektro UMSB - Bukittinggi ,Teknik
Elektro ISTN Jakarta Jurnal Teknik Elektro ITP, Januari 2012 Sistem Pengendali Arus Start Motor Induksi Phasa Tiga dengan Variasi Beban Jurnal Teknik Elektro ITP, Volume 1, No. 2; Januari 2012 SISTEM PENGENDALI ARUS START MOTOR INDUKSI PHASA TIGA DENGAN VARIASI BEBAN.

[11] Sudaryatno Sudirham, Analsis Rangkaian Listrik (1) Fasor, Impedansi, dan Kaidah Rangkaia 8 Makalah Seminar Tugas Akhir. Analisis rangkaian listrik di kawasan fasor

[12] Warsih ${ }^{[1]}$, Darjat, S.T, M.T ${ }^{[2]}$, Iwan Setiawan, S.T, M.T [2] j Jurnal, Jurusan Teknik Elektro, Fakultas Teknik, Universitas Diponegoro Jln. Prof. Sudharto, Tembalang, Semarang, Indonesia 9 .

[13] Pustekom Depdiknas (C2008 Analisis gelombang sinusoidal

[14] Muchlishah FT, UI,2008 Jurnal, Simulasi unjuk kerja motor induksi

[15] Dosen FT.Elektro, Monitoring motor induksi 3 - fase mengunakan sofware Lab VIEW berbasis webserver.

[16] Diktat training LabVIEW, laboratorium dinamika - PPU ITB, 2005.

[17] Warsih, Implementasi Lab VIEW 8.2 Jurnal, Pada pengaturan mesin AC berbasis sensor PIB325, Univ. Diponegoro

[18] Zuhal.1993.Dasar Teknik Tenaga Listrik dan Elektronika Daya. Gramedia Pustaka Utama, Jakarta Diposkan oleh Gizha di 05.09 Rangkaian Listrik FASOR ( Analisis fasor,Faktor daya dan perhitungan tiga fasa) fasor gelombang sinusoid

[19] Google Web - Fasor dan impendansi pada elemen- elemen dasar rangkaian listrik.

[01] National instruments, LabVIEW system Design Software online 2013. http://www.ni.com/labview. 
